\title{
British International Education: Policies Implemented, International Students Mobility (ISM) and Statistical Basis
}

\author{
Zixuan Chen ${ }^{1, *, \dagger}$, Hongyu $\mathrm{Li}^{2, *, \dagger}$ \\ ${ }^{1}$ University College London (UCL), Gower St, London WC1E 6BT, United Kingdom \\ ${ }^{2}$ Florida International University, 11200 SW 8th St, Miami, FL 33199, United States \\ ${ }^{*}$ Corresponding author. Email: ${ }^{1}$ zixuan.chen.20@ucl.ac.uk, ${ }^{2}$ hli047@fiu.edu
}

${ }^{\dagger}$ Both of the authors contributed equally.

\begin{abstract}
Policies on international students in the UK always show a strong impact on the UK higher education and society. This essay focuses on drawing a statistics-based analysis on the relations between international students and UK higher education. When analyzing the motivation of international students' decisions to receive higher education abroad, this essay indicates this from the "push-pull model" perspective and tells what factors can be counted as the keys to influence international students' decisions. To understand how international students are exactly impacted by the policies implemented, "International Student Mobility (ISR)" is introduced, with the demonstration of policies implemented for international students that brought significant changes to higher education (HE) from 2004 to 2010. When finding the statistical evidence as to the proof of the correlation between qualitative research, quantitative research and ex post facto research are all introduced in this essay to illustrate our claim from various angles. The explanations of the statistics can be concluded that even if the changing of students' policies can determine ISM, the policy implemented does not harm their existing students. Lastly, mutual benefits between international students and UK society cannot be ignored. This essay explains the factors as vital elements that are beneficial for each side to propose a more critical and inclusive policy in the UK from a higher education perspective in the future.
\end{abstract}

Keywords: International Student Mobility (ISM), Higher Education (HE), UK International Students, Policies and Government.

\section{INTRODUCTION}

It is increasing the case that more and more students began to choose to study out of their nations for better higher educational resources. According to the statistics, there are "more than four billion students" [1] who travel abroad for advanced education (higher education) annually. Higher education begins to become a typical and significant industry for certain countries with advanced higher educational resources, such as the US, Canada, Australia, and the UK, enabling the "direct currency exchange" [2]. Clearly, international students become one of the most important factors for countries to compete in the international economic market and a vital element to determine the world ranking for certain universities. In this case, universities in the UK have implemented many policies to attract international students and compete with universities from other nations. As the statistics from UNESCO and Higher Education Statistics Authority (HESA) suggest, policies for international students have been changing over time, and the numbers of international students also fluctuate as the policies change. Some of the research demonstrates that the policies implemented would have been correlated with the decisions of students to choose the country they would like to study for HE - particularly. We call this "international student mobility (ISM)".

Generally, "international student mobility" can be referred to as changing the number of students going to their determining countries for higher education. In studies, the reasons for changing ISM can be explained from the "push-pull model" [2]. The "push" model is also known as the national motivation of students' original 
countries - how they "push" them to study abroad. Normally the reasons can be explained by, for example, "low higher educational quality", "limited places in HE institutions," or "bad domestic economic development" [2]. As for the pull model, however, international students would be more likely to be attracted by their destination countries for some of their special properties. For example, countries would provide "better part-time job opportunities" [2], better higher education resources and university rankings or more "thriving economics" [2], which makes their higher education more likely to achieve greater success from their perspectives. It should be pointed out that the "push-pull" model should be understood based on the general evaluation of the "HE education market" [3], and students should make decisions of choosing HE destination as the "rational economic actor" [3]. For the "pull-model", the factors that "pull" international students can be seen as "capitals" these countries have for their higher education. Speaking of the capitals, it is an important factor of attracting students in which it helps to input the "production function" [4]. From the Bourdieusian perspective, ISM is positioned as the "accumulated factor" [5] to compete with higher educational institutions in $\mathrm{HE}$ as an economic market for particular countries.

\subsection{International Students in the UK}

It is demonstrated that international students come to the UK generally for further education and higher education. Some of the students may go to English language schools or independent schools. Among these, Higher education tends to be the largest education sector for independent students. From HESA, the population of both international undergraduate and postgraduate students constantly increased from the year 2012 to the year 2018 - to be specific, undergraduate students increased from $1,528,495$ to $1,597,825$ people [6], the increasing population of international students also brings a large number of visa issued annually - according to UK government, around 300,000 study visas needs to be issued each year[7], including the Tier 4 visas and those who are going to have a short-term study in the UK for less than one year.

Higher educational institutions, as the largest education sector for all the UK international students, make up $80 \%$ of the Tier 4 visa sponsorship - in 2016/2017, there are more than 235,000 first-year international students of higher education, and non-EU students make up $73 \%$ of this population. Among all the non-EU students, Chinese students make up the largest population and become the most common country where students come from. For this, a research project from Bright Future explains this from their quantitative research. Among 8,000 participants (all of them are UK international students from the People's Republic of China) from their research, over $93 \%$ of the students regard UK university degree as "high-quality education" as they are generally appeared to be very sensitive to the global university ranking - according to the QS university rankings in 2022, there are $17 \mathrm{UK}$ universities that are ranked as top 100 universities in the world.

Certainly, UK universities always take advantage of the global rankings, and this becomes one of the key factors to attract Chinese students since categorizing and ranking schools and institutions based on their capabilities, reputation. Students' academic achievement has been quite an "official and common practice" in China. According to Soysal and Woodman, global university rankings aim to create "world-class higher education institutions" [2] which meet the demand of many non-EU international students and can be counted as one of the strategic policies set for international students.

Previous research shows limited explorations and evaluations in terms of how policies of UK universities for international students are changed due to the changing general background of UK society in each period. Therefore, it is sometimes hard to analyze how UK society impacts International Student Mobility. This essay aims to demonstrate how the UK general policies implemented relate to the ISM and examine to what extent ISM influenced the UK policies for international students in universities. Besides these, this essay also points out how the UK government and international students are mutually benefited from understanding why the policies are implemented over time from international students' perspectives.

\subsection{UK Higher Educational Policies for International Students}

From 2004, UK educational policy towards international students has experienced some significant changes as key factors influencing the International Students' mobility [2]. From Lomer, the discourse of policies can be linked to student mobility, especially in 2010 - the tightening of immigration policies negatively impacted international students' mobility [2]. Generally, UK policies towards international students can be divided into three stages.

The first stage occurred in 2004 when the Post-study Work (PSW) route was introduced. Between 2004 and 2008, various schemes were introduced to allow all the graduates from UK higher education institutions to work and find jobs in the UK ranging from 12 to 24 months. The providing of job vacancies did attract lots of international students over the years. According to figure1, international students of all kinds kept increasing, and especially in China, significant growth of international students' population increased from about 300,000 to 350,000 . 


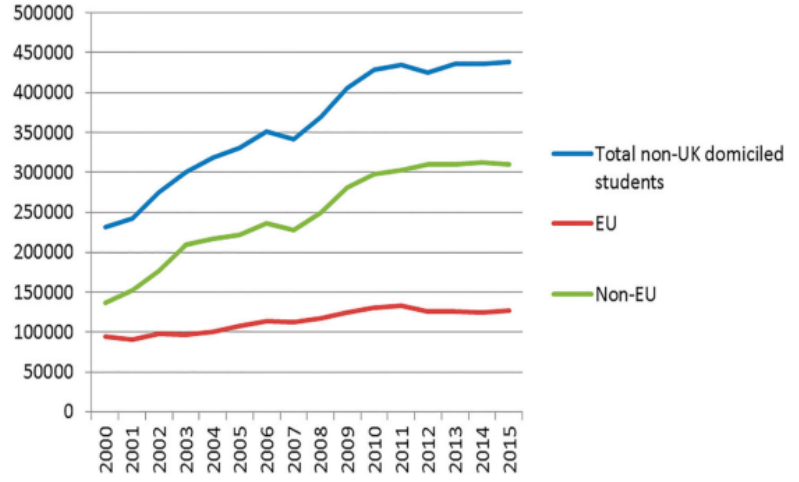

Figure 1 Absolute numbers of non-UK domiciled students in the UK 2000-2015 (HESA 2017).

The second important stage occurred in 2009, when the "Tier4 route launched, aiming to simplify the immigration system" for international students and educators, the purpose of the policy implemented was to provide a more "transparent visa application process". Students who were awarded the points if they meet an objective scoring test requirement prove that they have "sufficient funds to maintain themselves".

The last important stage occurred in 2010, as the tightening of immigration policy (which is still restricted until now and somehow influences international students' mobility in the UK). Students' working hours were restricted to 10 hours when "studying below degree level". As the restriction of illegal work from multiple small colleges [8] also operated as the tightening of students' visa system: language requirements were raised, stricter interview of credibility was introduced, and "post-study" work visa was eliminated. The policy decreased many possibilities of international students studying in the UK, as the loss of "acceptable candidates" and the overall migration reduced.

\section{METHODOLOGY: TARGET POPULATION, DATA COLLECTION INSTRUMENTS, AND ANALYSIS}

This research employs several research methodologies that are critical in helping obtain the desired data that is key in giving the right decision and conclusion. International education has several factors that make it necessary to understand, and the information is found in various places that provide the best idea of what is happening. In this research, both the quantitative and qualitative research methods are employed to give the best results. The quantitative analysis is mostly about the numbers for those who get to be part of the international studies and the different regions that accumulate to produce particular students during particular periods [9].

This collection of numerical data helps research and get the actual figures of those studying abroad. The student mobility number does change over time, and these statistics can be collected from various places. In this case, the primary data that is used is the secondary data. They are not sampled but collected as can be found in the systems. The research data collection, in this case, is from the governments, libraries, and past research that has been conducted as well. The higher education Institutions do have various data from the international students. Hence, these data are remitted to the Higher Education statistics agency, thus giving a clear indication of the number of international students [10].

Ex post facto research method is the other method that the research has been conducted. This method tries to find a current situation and, in this case, the enrollment of more international students and dig deep into what may have been the cause for it in the past [11]. This is the best because the research is not majorly experimental but rather a state that is already happening. In this case, the cause and effect of particular scenarios get to be analyzed.

\subsection{Target Population}

A population is referred to like elements that are key in us making particular inferences. In this case, the population is a subject such as a student, an institution, a nation, or quantitative data. The target population, in this case, are all international students in the United Kingdom.

\subsection{Data Collection Instruments}

This study used secondary data to obtain the correct number and figures from the bodies in charge of detailed statistics [12]. Hence, this was collected from the higher education statistics agency, which gets the data from the various higher education institutions. The Times higher education world ranking data was also used to match with those of the United Kingdom institutions to see the multiple variances in the intake of international students and the motivation.

\subsection{Analysis}

The qualitative and quantitative data are analyzed in various ways as per the guidelines. The qualitative data is explored through narrative analysis as well as content analysis. The multiple methods get to give an understanding of the provided data and why specific actions are taken. The quantitative data are analyzed using various hypotheses and use of the numbers that are in play. The means are also used in a form in which they help guide on the trends. 


\section{THE ECONOMIC BENEFITS OF INTERNATIONAL STUDENTS FROM THE UK'S PERSPECTIVE}

In many studies on the mobility of international students, economic factors cannot be ignored. It can be seen from many key policy positions in the UK that international students are considered the role of consumers because of their outstanding contribution to the UK economy [2]. The positive economic benefits that international students bring to the UK are not only through the payment of tuition fees but also through the cost of living in the UK and the travel expenses for parents and friends to visit the UK. These benefits are widely disseminated in the UK, and international students benefit from public finances through their financial contributions and the relative lack of public resources, such as student loans.

\subsection{Tuition Fees, Living Expenses, and Others}

From the three policy periods mentioned above, it is not difficult to find common ground: international students are regarded as a source of income. First of all, the most important and direct is the tuition fees paid by international students studying in the UK. The HESA [13] summarizes the source of income contributed by each source of higher education providers and the growth over time or other methods. As can be seen from Table 1 , tuition fees and education contracts account for nearly $50 \%$ of all income. From 2015/16 to 2016/17, total revenue increased by $2.7 \%$. Tuition and education contracts increased the most (5.5\%), from 16.8 billion pounds in 2015/16 to 17.7 billion pounds. This continues to be affected by changes in the funding system. And international students accounted for $32.6 \%$, which is also an increase from before.

Table 1. Income by source $2016 / 17$ and $2015 / 16$

\begin{tabular}{llll}
\hline Income & $2016 / 17$ & $2015 / 16$ & $\%$ Change \\
\hline Tuition fees and education contracts & 17742257 & 16811104 & $5.5 \%$ \\
Funding body grants & 5105432 & 5166655 & $-1.2 \%$ \\
Research grants and contracts & 5915926 & 5885905 & $0.5 \%$ \\
Other income & 6067425 & 6044943 & $0.4 \%$ \\
Investment income & 253554 & 261407 & $-3.0 \%$ \\
\hline Total income before donations and endowments & 35084594 & 34170014 & $2.7 \%$ \\
Donations and endowments & 585813 & 577880 & $1.4 \%$ \\
\hline Total income & 35670407 & 34747894 & $2.7 \%$ \\
\hline
\end{tabular}

At the same time, their living expenses are also a big income. In a report for the University of Sheffield [14], the total living expenses of Sheffield international students is 76.8 million pounds. At the regional level, total living expenses directly contributed 54.7 million pounds to GDP. Finally, the consumption of relatives and friends of visiting international students also generated income. In a report for the University of Sheffield [14], these tourists will spend a total of $£ 5.9$ million in Sheffield during the 2012/13 academic year.

\subsection{Fiscal Impacts}

In addition to the direct income mentioned above, international students also contribute to some potential economic benefits, such as public finances. The MAC paper [15] of the Oxford Institute for Economic Research studies the impact of immigration on the European Economic Area. Through analysis, we find that international students receiving higher education have a very obvious impact on the UK's finances, and all their living expenses in the UK represent tax contributions. Table 2 [16] collects data related to the economic contribution of international students in the UK after graduation in 2016/17. EU students contribute approximately $£ 32,000$ in income tax to the UK's finances, while non-EU international students contribute $£ 31,000$. In addition, with the enhanced human capital of graduate students and higher income in future development, we can see that the tax generated by graduate students and above will be higher, and the specific amount is as high as 41,000 pounds or even 45,000 pounds.

Table 2. Post-graduation tax statistics related to 2016/17 international students

\begin{tabular}{|c|c|c|c|c|c|c|}
\hline \multirow[t]{2}{*}{ Level of study } & \multicolumn{3}{|c|}{ Average $£$ per graduate } & \multicolumn{3}{|l|}{ Total } \\
\hline & EU & Non-EU & Average & EU & Non-EU & Total \\
\hline Other & $£ 32,000$ & $£ 32,000$ & $£ 32,000$ & $£ 19 m$ & $£ 34 m$ & $£ 53 m$ \\
\hline
\end{tabular}

undergraduate 


\begin{tabular}{|c|c|c|c|c|c|c|c|}
\hline First degree & & $£ 32,000$ & $£ 31,000$ & $£ 31,000$ & $£ 179 m$ & $£ 184 m$ & $£ 363 \mathrm{~m}$ \\
\hline $\begin{array}{l}\text { Higher } \\
\text { (taught) }\end{array}$ & degree & $£ 41,000$ & $£ 34,000$ & $£ 36,000$ & $£ 150 m$ & $£ 374 m$ & $£ 525 \mathrm{~m}$ \\
\hline $\begin{array}{l}\text { Higher } \\
\text { (research) }\end{array}$ & degree & $£ 45,000$ & $£ 45,000$ & $£ 45,000$ & $£ 40 \mathrm{~m}$ & $£ 62 \mathrm{~m}$ & $£ 102 m$ \\
\hline Average & & $£ 36,000$ & $£ 34,000$ & $£ 35,000$ & & & \\
\hline Total & & & & & £388m & $£ 655 \mathrm{~m}$ & $£ 1,043 \mathrm{~m}$ \\
\hline
\end{tabular}

Except for the well-known tax revenue, student loans are ignored by most people as income. According to data from Student Loan Corporation (SLC) [17], in 2017, 73\% of EU international students can apply for student loans, and $94 \%$ of local students in the UK can apply for student loans. Compared with British students, it is more complicated for EU students to apply for student loans. In addition, it can be found from Figure 2 that the average loan amount of EU students is much lower than that of UK students. In 2017/18, the total public debt of all students was 104.6 billion pounds; this amount was divided into 104.2 billion pounds living in the UK (98\%) and 2.2 billion pounds living in the EU ( $2 \%)$. However, according to the MAC report [15], the average repayment of EU students who pay tuition fees is higher than that of British students. The current research on this phenomenon is not enough to accurately assess the repayment rate of student loans provided to international students. Therefore, we believe that we can further support the point mentioned above by increasing the research on the comparison of the average repayment of British students and international students.

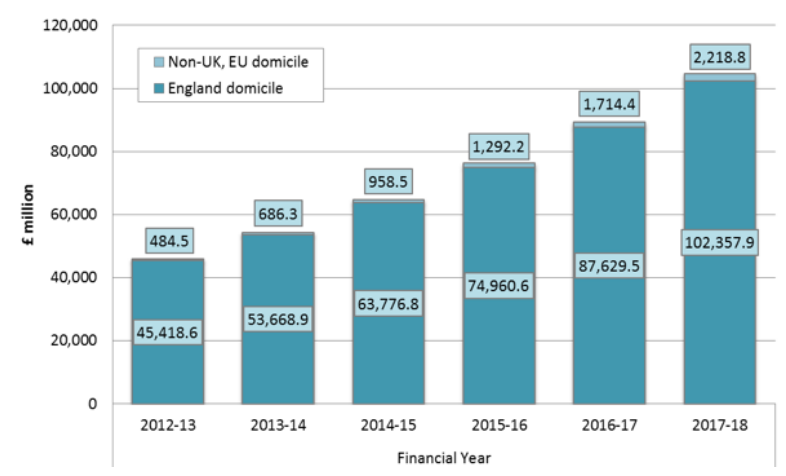

Figure 2 Total balance of income HE student loans from $2012-13$ to $2017-18$

\section{THE BENEFITS OF STUDYING IN THE UK FOR INTERNATIONAL STUDENTS}

The United Kingdom, which is very competitive in the global education market, can bring many benefits to international students. International students may be attracted to certain countries for reasons including perceptions and recognition of high-quality living and educational standards, the availability of part-time jobs, common language and colonial connections, existing social connections, and a booming economy [2].
In addition to the well-known job opportunities and immigration opportunities, the interests of academic exchanges are our main research direction. In other words, what we study is the real international higher education experience that international student get when they come to the UK to study [18].

In Lomer's research [2], through the analysis of policy changes (changes in factors that attract international students to study in the UK), it is found that the shrinking of the UK's policy for international students does not necessarily have a negative impact. In 2010, the immigration policy was changed, and the work route was canceled after graduation. Employment opportunities for international students are greatly hindered after graduation [19]. From Figure 3, we can see that the number of students from South Asian countries such as India and Pakistan have dropped by more than $20 \%$ since 2009/2010 [20]. However, this did not affect Chinese students. Since 2008/2009, the number of Chinese students studying abroad has increased by nearly $40 \%$.

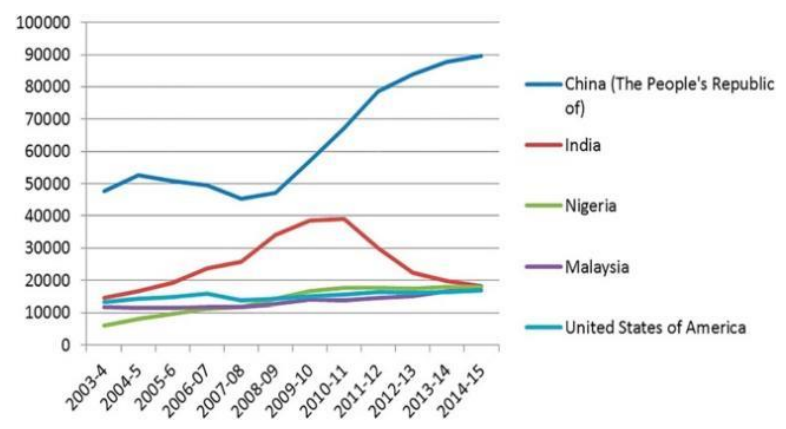

Figure 3 Number of international students from the top five source countries in the UK [2].

This may be related to the perception of the importance of academic qualifications relative to work experience in the British labor market [2]. This shows that the perceived value of Chinese students lies in academic qualifications, no work experience. From a consumer perspective, Chinese students equate education (or a degree) with a valuable benefit rather than an experience. Therefore, the total number of international students still increased in 2013 and was not significantly affected by the suppression of the British study abroad policy. 


\section{CONCLUSION}

In conclusion, this essay demonstrates "international student mobility (ISM)" as a key concept for analyzing international students' relations and UK universities. To understand what are the factors that may influence ISM, this essay illustrates the evidence from a "push-pull model" point of view [2], primarily from how students' original countries determine their decisions of studying abroad, as well as how their destination countries attract them to come and receive higher education. In order to understand how policies in destination countries and universities are deterministic in forming students' decisions, this essay provides both policies and statistics changes to indicate the correlation in between.

When analyzing the statistics, qualitative research method, quantitative research method and also ex-post method are introduced to study how our target population (international students in the UK) make decisions of whether they choose the UK and its universities as destinations of higher education - it is showed that students pay more attention to the factor such as part-time job availability, whether the immigrant policies are tightened and requirements of student's loans. Even if it is summarized that changing of student's policies determines ISM somehow, but policy implemented does not harm their existing students. According to the explanation, universities in the UK benefit from their tuition fees and living expenses as the support of economic growth, while international students benefit from higher education experiences abroad and degree certificates from competitive universities. This essay's statistics and analysis suggest that policies implemented are closely correlated to ISM and determine how students and UK society are mutually benefited. Thus, educational and international student policies should be more critical and inclusive to attract international students as a "main guest" [2] of British higher education and indispensable consumers of the UK educational market.

Even if this essay provides new insight into the correlation between UK higher education and its international students from mutual benefits, educational, social and economic aspects, limited statistical evidence found for recent years should also be pointed out as the limitation of our finding. Existing statistics on the policies changed for international students in the UK in recent three years and how these impact the numbers of international students annually are still circumscribed, leading to the limitation on the conclusive studies on the policy itself for UK international students in recent years. Therefore, this essay exists not only for providing new thoughts on the correlation between policies and international students from a historical perspective but also an inspiration to inform or motivate future research in this area, for instance, the recent policies and their significance, more primary sources on the ISM and ethical dimensions on the international students from a larger variety of angles.

\section{REFERENCES}

[1] E.M. Clarke, E.A. Emerson, Design and synthesis of synchronization skeletons using branching time temporal logic, in: D. Kozen (Eds.), Workshop on Logics of Programs, Lecture Notes in Computer Science, vol. 131, Springer, Berlin, Heidelberg, 1981, pp. 52-71.

[2] J.P. Queille, J. Sifakis, Specification and verification of concurrent systems in CESAR, in: $M$. Dezani-Ciancaglini and U. Montanari (Eds.), Proceedings of the 5th International Symposium on Programming, Lecture Notes in Computer Science, vol. 137, Springer, Berlin, Heidelberg, 1982, pp. 337-351.

[3] C. Baier, J-P. Katoen, Principles of Model Checking, MIT Press, 2008.

[4] M. Kwiatkowska, G. Norman, D. Parker, Stochastic model checking, in: M. Bernardo, J. Hillston (Eds.), Proceedings of the Formal Methods for the Design of Computer, Communication and Software Systems: Performance Evaluation (SFM), Springer, Berlin, Heidelberg, 2007, pp. 220-270.

[5] V. Forejt, M. Kwiatkowska, G. Norman, D. Parker, Automated verification techniques for probabilistic systems, in: M. Bernardo, V. Issarny (Eds.), Proceedings of the Formal Methods for Eternal Networked Software Systems (SFM), Springer, Berlin, Heidelberg, 2011, pp. 53-113.

[6] G.D. Penna, B. Intrigila, I. Melatti, E. Tronci, M.V. Zilli, Bounded probabilistic model checking with the muralpha verifier, in: A.J. Hu, A.K. Martin (Eds.), Proceedings of the Formal Methods in Computer-Aided Design, Springer, Berlin, Heidelberg, 2004, pp. 214-229.

[7] E. Clarke, O. Grumberg, S. Jha, et al., Counterexample-guided abstraction refinement, in: E.A. Emerson, A.P. Sistla (Eds.), Computer Aided Verification, Springer, Berlin, Heidelberg, 2000, pp. 154-169.

[8] H. Barringer, R. Kuiper, A. Pnueli, Now you may compose temporal logic specifications, in: Proceedings of the Sixteenth Annual ACM Symposium on the Theory of Computing (STOC), ACM, 1984, pp. 51-63.

[9] A. Pnueli, In transition from global to modular temporal reasoning about programs, in: KR Apt (Ed.), Logics and Models of Concurrent Systems, Springer, Berlin, Heidelberg, 1984, pp. 123-144. 
[10] B. Meyer, Applying "Design by Contract", Computer 25(10) (1992) 40-51.

[11] N. J., Salkind\& C. N., Silva. Ex post facto study. Encyclopedia of Research Design, 10(1), 2010, 466-467.

[12] P. Daas, \& J. Arends-Tóth. Secondary data collection. Statistics Netherlands. The Hague, 2012.

[13] HESA (Higher Education Statistics Authority). Students in Higher Education Institutions: 2016-17. 2017, Cheltenham: HESA.

[14] Oxford Economics. The Costs and Benefits of International Students in Sheffield A report for the University of Sheffield January 2013.

[15] MAC (Migration Advisory Committee).2018. Impact of international students in the UK. London Marsham Street

[16] G. Conlon, M. Halterbeck, \& S. Hedges. The UK's tax revenues from international students postgraduation, London Economics, the Higher Education Policy Institute (HEPI), 2019, pp. 28-29.

[17] J. L., Mateos-González, \& P. Wakeling. Student loans and participation in postgraduate education: the case of English master's loans. Oxford Review of Education, 46(6), 2020, 698-716.

[18] S. Lillyman, \& C. Bennett. Providing a positive learning experience for international students studying at UK UNIVERSITIES: A literature review. Journal of Research in International Education, 13(1), 2014, 63-75.

[19] S. Marginson. "International Students: The United Kingdom Drops the Ball." International Higher Education, 2014b, 76: 9-10.

[20] IEC (International Education Council). "International Education Council Working Group: Attracting Legitimate International Students to the UK." 2014. 